\title{
SCANDINAVIAN JOURNAL
}

\section{of}

\section{BEHAVIOUR THERAPY}

The Scandinavian Journal of Behaviour Therapy is a quarterly devoted to the rapid publication of original research reports, literature reviews, theoretical analyses and case studies within the broad framework of modern learning theory, behaviour therapy, and behavioural medicine. Manuscripts should conform to APA style and be written in English or a Scandinavian language. The journal makes no page charges. Three copies of the manuscript may be submitted to the editor at the address below.

The journal in indexed in: Psychological Abstracts

Behavioural Abstracts

Sage Family Studies

Psychological Readers Guide

\section{SUBSCRIPTION ORDER FORM}

Please enter my subscription to The Scandinavian Journal of Behaviour Therapy

Special foreign rate: $\$ 15.00$ (outside of Europe)

In Europe: $\quad 90: 00$ SEK

name

address

city

state
Please return to:

STEVEN J. LINTON PhD

Dept. of Occupational Medicine

Orebro Medical Centre Hospital 70185 OREBRO

Sweden 
ISSUES AND

APPROACHES IN

PERSONAL CONSTRUICT

THEORY

\section{Edited by Donald Bannister}

April 1985, 302pp., \$46.50/£37.00 (UK only), ISBN: 0.12.077980.3

In the light of the still growing interest in George Kelly's ideas and as a follow up to the widely read perspectives volumes, this book presents extensive reports of recent developments in personal construct theory.

Areas discussed are self construing in children, attitudes of parents of the mentally handicapped, self diagnosis by psychiatric patients, suicide, the teaching of teachers, self organised learning and the meaning of construct theory for issues such as emotion, choice, bodily experience and reflective conversation. Also included is a major sociohistorical analysis of the way Kelly's theory has developed since 1950 and an examination of its philosophical basis.

Prices are subject to change without notice
ANXIETY

Psychological Perspectives on Panic and Agoraphobia

Richard S. Hallam

1985, 206pp., \$35.00/£30.00 (CK only), ISBN: 0.12 .319620 .5

This volume analyses the perplexing and often disabling form of distress known as anxiety from a psychological rather than a biomedical perspective, illustrating the rich contribution that psychological theory has made and is making to this topic. The first section extensively examines the clinical literature, describing and delineating with case examples the cluster of characteristic features termed panic-anxiety. Research findings in other clinical areas such as alcohol dependence are shown to have conceptual and empirical links with panic-anxiety. The second section of the book reviews and evaluates the main theoretical approaches to anxiety, including specific models of panic and agoraphobia, challenging many traditional assumptions and advocating the analysis of anxiety as a socially constructed meaning imposed on experience rather than a theoretical concept or psychopathological state. The methodological implications are discussed and a schematic model of panic-anxiety is proposed.

\section{ACADEMIC PRESS}

publishes books and journals in many areas of Science including:

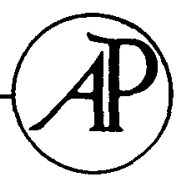

Acoustics, Agriculture, Anatomy, Anthropology, Archaeology, Audiology - Biochemistry, Biology, Botany • Cancer research, Cardiology, Chemistry, Computer science - Economics, Engineering, Environmental science - Food science • Geography, Geology - Immunology - Materials technology, Mathematics, Microbiology · Neuroscience, Nutrition • Oncology, Ornithology • Pathology, Pharmacology, Physics, Physiology, Psychiatry, Psychology · Religion · Sociology, Speech, Surgery • Toxicology • Virology · Zoology

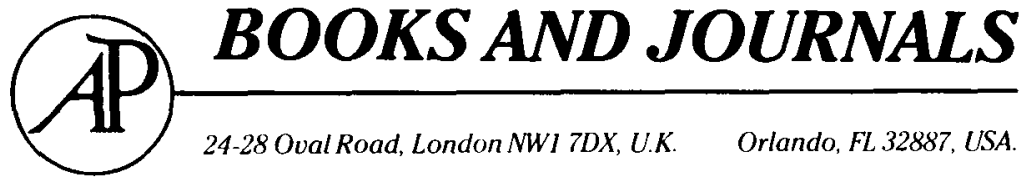




\section{Instructions to Authors}

1. Submission. Articles, written in English and not submitted for publication elsewhere, should be sent to Dr A. Desmond Poole, Department of Mental Health, The Queen's University of Belfast, Windsor House, Belfast City Hospital, Belfast BT9 7AB, Northern lreland.

2. Manuscript preparation. Four complete copies of the manuscript must be submitted. Original figures should be supplied at the time of submission. Articles must be typed double-spaced throughout on standard sized paper (preferably A4) allowing wide margins all round. Where unpublished material, e.g. behaviour rating scales, therapy manuals, etc is referred to in an article, copies should be submitted to facilitate review.

Manuscripts will be sent out for review exactly as submitred. Authors who want a blind review should mark two copies of their article "review copy" omitting from these copies details of authorship.

Abbreviations where used must be standard. The Systeme Internationale (SI) should be used for all units where metric units are used the SI equivalent must also be given. Probability values and power statistics should be given with statistic values and degrees of freedom [e.g. $F(1,34)=123.07, P<0.001]$, but such information should preferably be included in tables rather than the main texr.

Spelling must be consistent within an article, either using British usage (The Shorter Oxford English Dictionary), or American usage (Webster's Neu. Collegiate Dictionary). However, spelling in the list of references must be literal to each original publication.

Details of style not specified here may be determined by reference to the Publication Manual of the American Psychological Association or the Style Manual for Biological Journals.

Articles should conform to the following scheme:

(a) Title page. The ritle should phrase concisely the major issues. Author(s) to be given with departmental affiliations and addresses, grouped appropriately. A running head of no more than 40 characters should be indicated.

(b) Summary. This should summarize the article in no more than 200 words.

(c) Text. This should begin with an introduction, succinctly introducing the point of the paper to those interested in the general area of the journal. References within the text should be given in the form Jones and Smith (1973). Three or more authors should be given as Williams et al. (1973). Authors of the same surname should be distinguished by their initials. The approximate positions of tables and figures should be indicated in the text. Footnotes should be avoided where possible.

(d) Reference note(s). A list of all cired unpublished or limited circularion material, numbered in order of appearance in the text, giving as much information as possible about extant manuscripts.

(e) References. All citations in the text should be listed in strict alphabetical order according to surnames. Multiple references to the same author should be listed chronologically, using a, b. etc., for entries within the same year. Formats for journal articles, books and chapters should follow these examples:

BeCKer, M. R. and GreEN, L. W. (1975). A family approach to compliance with medical treatment: A selective review of the literature. International Journal of Health Education 18, 173-182.

THORP, R. G. and WeTzeL, R. J. (1969). Behaviour Modification in the Natural Emironment. New York: Academic Press.

Roskies, E. and Lazarus, R. S. (1980). Coping theory and the teaching of coping skills. In Bebavioural Medicine: Changing Health Lifestyles. P. O. Davidson and S. M. Davidson (Eds), New York: Brunner/Mazel.

(f) Footnotes. The first, and preferably only, foornote will appear at the foot of the first page of each article, and subsequently may acknowledge previous unpublished presentation (e.g. dissertation, meeting paper), financial support, scholarly or technical assistance, or a change in affiliation. Its concluding (or only) paragraph must be the name and full mailing address of the author to whom reprint requests or other inquires should be sent.

(g) Tables. Tables should be numbered and given explanatory tirles.

(h) Figure captions. Numbered captions should be typed on a separate page.

(i) Figures. Original drawings or prints must be submitted for each line or half-tone illustration. Figures should be clearly labelled.

3. Proofs, Reprints and Copyright. Proofs of accepted articles will be sent to authors for the correcrion of printers' errors; author's alterations may be charged. Authors submitting a manuscript do so on the understanding that if it is accepted for publication exclusive copyright in the paper shall be assigned to the Society. In consideration of the assignment of copyright, 25 copies of each paper will be supplied. Further reprints may be ordered at extra cost; the copyright assignment form and the reprint order form will be sent with the proofs. The publishers will nor put any limitation on the personal freedom of the author to use material contained in the paper in other works. 
